\title{
Pregnancy outcome after diagnosis of oligohydramnios at term
}

\author{
Shiva Kumar H C Hiriyur Chidanandaiah, Chandrashekhar K, Suman Gaddi, \\ Chandrashekhar T Tharihalli \\ Correspondence: Dr Shiva Kumar H C Hiriyur Chidanandaiah, Associate Professor, \\ Department of Obstetrics and Gynaecology, Vijayanagara Institute of Medical Sciences, \\ Bellary, Karnataka, India; Email - dr.hcshivkumar@gmail.com
}

Distributed under Creative Commons Attribution-Share Alike 4.0 International.

\begin{abstract}
Objectives: The aim of the study was to evaluate the effects of oligohydramnios on maternal and fetal outcome at term pregnancy. Methodology: A case control study on pregnancy outcome in 100 women with AFI $<5 \mathrm{~cm}$ after 37 completed weeks of pregnancy compared with 100 controls with no oligohydramnios with matched age and parity. Results: Non stress test (NST) was non-reactive in 38\% of oligohydramnios and $20 \%$ of controls and was statistically significant $(\mathrm{P}<0.05)$. Ominous fetal heart patterns were seen in $60 \%$ of oligohydramnios and $30 \%$ of controls but it was statistically not significant. Thick meconium stained amniotic fluid was seen in $48 \%$ of oligohydramnios and $20 \%$ of the controls and was significant $(\mathrm{P}<0.001)$. In oligohydramnios, $54 \%$ were induced whereas in controls, only $24 \%$ and was significant $(\mathrm{P}<0.002)$. For fetal distress, $88 \%$ of oligohydramnios and $90 \%$ of controls underwent LSCS and was not significant. APGAR score $<7$ was insignificant between the two groups. LBW and NICU admission were more in oligohydramnios and was significant $(\mathrm{P}<0.05,<0.01)$. Perinatal mortality was not significant between the two groups. Conclusion: Oligohydramnios $(\mathrm{AFI}<5)$ is valuable for predicting fetal distress in labour requiring caesarean section, used as an adjunct to other fetal surveillance methods. Oligohydramnios (AFI $<5 \mathrm{~cm}$ ) detected after 37 weeks of gestation is an indicator of poor pregnancy outcome.
\end{abstract}

Keywords: AFI, perinatal morbidity, LBW.

Nature has made of amniotic fluid cavity filled with liquor amnii, as floating bed for the fetus, for its growth in sterile environment, regulation of temperature, avoidance of external injury and reduction of impact of uterine contractions. Amniotic fluid Index (AFI) by four quadrant technique via transabdominal ultrasonography (USG), better identifies fetus at high risk than clinical estimation of amniotic fluid ${ }^{1}$.
Amniotic fluid index (AFI) of $\leq 5 \mathrm{~cm}$ is oligohydramnios as, described by Phelan et $\mathrm{al}^{2}$. It has been correlated with increased risk of intrauterine growth retardation, meconium aspiration syndrome, severe birth asphyxia, low APGAR scores and congenital abnormities ${ }^{1,2}$. Oligohydramnios is also associated with maternal morbidity in form of increased rates of induction and/or operative

Received: $8^{\text {th }}$ March 2017. Accepted: $15^{\text {th }}$ May 2017.

Chidanandaiah SKHCH, Chandrashekhar K, Gaddi S, Tharihalli CT. Pregnancy outcome after diagnosis of oligohydramnios at term. The New Indian Journal of OBGYN. 2017; 4(1):37-41 
interference ${ }^{3}$. Increased induction of labor and elective caesarean deliveries are currently practiced for better perinatal outcome.

The etiology, management and the outcome is different in late onset oligohydramnios compared to early onset oligohydramnios. Studies show that amniotic fluid index is a poor predictor of adverse outcome ${ }^{3}$.

Thus this study is conducted to find out the value of oligohydramnios in perinatal outcome and maternal outcome in pregnancies beyond 37 completed weeks.

\section{Materials and Methods}

After approval of Institutional Ethical Committee, proper counseling and consent of patients, study was conducted from March 2016 onwards in Department of OBG, VIMS, Bellary. Hundred (100) number of consecutive patients with diagnosis of oligohydramnios (with AFI $\leq 5 \mathrm{~cm}$ ) by ultrasound after 37 completed weeks selected after satisfying inclusion and exclusion criteria and compared with 100 controls without oligohydramnios and matched for other variables like age, parity, gestational age and any pregnancy complication.

Inclusion Criteria- 1) Singleton pregnancy with cephalic presentation, 2) pregnancies after 37 completed weeks of gestation, 3) AFI $<5 \mathrm{cms}$ with intact membranes.

Exclusion Criteria- Antenatal patients having polyhydramnios, premature rupture of membranes, twins and multiple pregnancies, congenital malformations.

A detailed history and examination were done. For all the women, ultrasound examination was done and amniotic fluid index was calculated by four quadrant amniotic fluid volume measurement technique. Oligohydramnios was confirmed by measuring AFI $<5$ $\mathrm{cm}$. The amniotic fluid volume is considered normal if amniotic fluid index is between 5.1 and $20 \mathrm{~cm}$. All cases were monitored by continuous electronic fetal monitoring in labor. Those who developed significant variable decelerations and repetitive late decelerations or other ominous FHR pattern with or without meconium stained liquor which persisted inspite of corrective measures like change in maternal position, hydration, $\mathrm{O}_{2}$ inhalation and stopping oxytocin were delivered by LSCS or forceps delivery. After $3 \mathrm{~cm}$ dilatation of the cervical os in primigravida and $4 \mathrm{~cm}$ dilatation in multigravida artificial rupture of membranes was done. Cases with thick meconium stained liquor was taken for emergency LSCS. Study was conducted to observe outcome of labour in form of spontaneous or induced labour, modes of delivery and perinatal outcome like fetal distress, APGAR scores of newborn, birth weight, NICU admission and neonatal mortality.

Data were collected in structured proforma and analysis was done with suitable statistical tools. Frequency distribution and chi-square tests were applied to analyse the data. $\mathrm{P}$ value of less than 0.05 was taken as statistically significant.

\section{Results}

The mean age for study group was 23.5 years and that of control group was 22.5 years. The mean gravidity was 1.8 and 1.6 and mean parity was 0.6 and 0.6 respectively for cases and controls. The mean gestational age was 39.2 weeks for study group and 39.6 weeks for control group which was similar.

Idiopathic (58\%) was the most common cause of oligohydramnios. PIH (32\%) and post term (10\%) pregnancy were other causes of oligohydramnios. The mean AFI for study group was $3.55 \mathrm{~cm}$ and control group was $9.55 \mathrm{~cm}$ [table 1].

Oligohydramnios is
associated with more number of non-reactive NST $(38 \%)$ as compared to controls (20\%).There was statistically significant difference between the two groups in the occurrence of non-reactive and reactive NST $(\mathrm{p}<0.05) \quad$ [table 2]. Table 1: Distribution of Amniotic Fluid Index (AFI)

\begin{tabular}{ll}
\hline AFI in cm & Number \\
\hline Study group & \\
$<2$ & 4 \\
$2-3$ & 30 \\
$3.1-4$ & 26 \\
$4.1-5$ & 40 \\
Total & 100 \\
Control group \\
$5-8$ & 38 \\
$8.1-11$ & 26 \\
$11.1-14$ & 28 \\
$14.1-17$ & 8 \\
Total & 100 \\
\hline
\end{tabular}

Most common FHR abnormality included variable deceleration which was considered significant if it was 
Table 2: Distribution of Non-stress test, Variable fetal heart rate pattern and Nature of amniotic Fluid in oligohydramnios and controls

\begin{tabular}{lccccc}
\hline Category & \multicolumn{2}{c}{$\begin{array}{l}\text { Study } \\
\text { group }\end{array}$} & \multicolumn{2}{c}{$\begin{array}{l}\text { Control } \\
\text { group }\end{array}$} & P-Value \\
& No & $\%$ & No & $\%$ & \\
\hline $\begin{array}{l}\text { Non Stress Test } \\
\text { Reactive }\end{array}$ & 62 & 62 & 80 & 80 & $\mathrm{P}<0.05$ \\
$\begin{array}{l}\text { Non reactive } \\
\text { Abnormal fetal heart rate }\end{array}$ & 38 & 38 & 20 & 20 & \\
$\begin{array}{l}\text { Variable } \\
\text { deceleration }\end{array}$ & 40 & 40 & 18 & 18 & \\
$\begin{array}{l}\text { Late } \\
\text { deceleration }\end{array}$ & 20 & 20 & 12 & 12 & \\
$\begin{array}{l}\text { Total } \\
\text { Nature of amniotic fluid }\end{array}$ & 60 & 60 & 30 & 30 & \\
$\begin{array}{l}\text { Clear } \\
\text { Thin meconium }\end{array}$ & 40 & 40 & 74 & 74 & \\
$\begin{array}{l}\text { Thick } \\
\text { meconium }\end{array}$ & 12 & 12 & 6 & 6 & \\
Total & 48 & 48 & 20 & 20 & $\mathrm{P}<0.001$ \\
\hline
\end{tabular}

Table 3: Distribution of oligohydramnios and mode of termination, mode of delivery and interventions for fetal distress

\begin{tabular}{|c|c|c|c|c|c|}
\hline \multirow[t]{2}{*}{ Category } & \multicolumn{2}{|c|}{$\begin{array}{l}\text { Study } \\
\text { group }\end{array}$} & \multicolumn{2}{|c|}{$\begin{array}{l}\text { Control } \\
\text { group }\end{array}$} & \multirow[t]{2}{*}{ P-Value } \\
\hline & No & $\%$ & No & $\%$ & \\
\hline \multicolumn{6}{|c|}{ Mode of Termination } \\
\hline Induced & 54 & 54 & 24 & 24 & \\
\hline Spontaneous & 46 & 46 & 76 & 76 & $\mathrm{P}<0.002$ \\
\hline Total & 100 & 100 & 100 & 100 & \\
\hline \multicolumn{6}{|c|}{ Modes of delivery } \\
\hline $\begin{array}{l}\text { Normal vaginal } \\
\text { delivery }\end{array}$ & 40 & 40 & 72 & 72 & \\
\hline LSCS & 48 & 48 & 22 & 22 & \\
\hline Forceps delivery & 12 & 12 & 6 & 6 & \\
\hline Total & 100 & 100 & 100 & 100 & \\
\hline \multicolumn{6}{|c|}{ Interventions for fetal distress } \\
\hline LSCS & 44 & 44 & 18 & 18 & \\
\hline $\begin{array}{l}\text { Instrumental } \\
\text { Deliveries }\end{array}$ & 6 & 6 & 2 & 2 & $\mathrm{P}=0.98$ \\
\hline $\begin{array}{l}\text { Total } \\
\text { interventions }\end{array}$ & 50 & 50 & 20 & 20 & \\
\hline
\end{tabular}

below $70 \mathrm{bpm}$ persisting for $>60 \mathrm{sec}$. The significant variable decelerations was noted in 40 women $(40 \%)$ and repetitive late deceleration in $20(20 \%)$ of women in oligohydramnios. In the control group 18(18\%) women developed variable decelerations and $12(12 \%)$ women had late deceleration. However, these ominous FHR were seen in those women of control group who had an AFI in the lower range. There was no significant difference in two groups in occurrence of FHR decelerations statistically $(\mathrm{P}=0.66) \quad$ table 2]. Oligohydramnios is associated with more number of women $(48 \%)$ with thick meconium

Table 4 : LSCS for fetal distress in Non-reactive \& Reactive NST

\begin{tabular}{lcll}
\hline Groups & $\begin{array}{l}\text { Non- } \\
\text { reactive } \\
\text { NST }\end{array}$ & $\begin{array}{l}\text { LSCS } \\
\text { for fetal } \\
\text { distress }\end{array}$ & $\begin{array}{l}\text { Percent- } \\
\text { age }\end{array}$ \\
\hline $\begin{array}{l}\text { Oligohydra- } \\
\text { mnios }\end{array}$ & 38 & 20 & $52.63 \%$ \\
Controls & 20 & 8 & $40.00 \%$ \\
Groups & $\begin{array}{l}\text { Reactive } \\
\text { NST }\end{array}$ & $\begin{array}{l}\text { LSCS } \\
\text { for fetal } \\
\text { distress }\end{array}$ & $\begin{array}{l}\text { Percent- } \\
\text { age }\end{array}$ \\
$\begin{array}{l}\text { Oligohydra- } \\
\text { mnios }\end{array}$ & 62 & 24 & $38.70 \%$ \\
Controls & 80 & 10 & $12.50 \%$ \\
\hline
\end{tabular}

stained amniotic fluid. The difference in occurrence of meconium stained amniotic fluid between two groups was statistically significant $(\mathrm{P}<0.001)$ [table 2].

The labour was induced in $54(54 \%)$ women with oligohydramnios and 24 (24\%) of controls. The decision for induction or allowing for spontaneous labour was made depending upon AFI, gestational age, presence of complications like preeclampsia, post term pregnancy, non reactive NST and favorability of cervix. The difference between two groups in this category was statistically significant $(\mathrm{P}<0.002)$ [table 3]. LSCS was done in 48 and forceps delivery in 12 cases of oligohydramnios. A total of $50(50 \%)$ women developed fetal distress in oligohydramnios. Among 50 women of fetal distress, $44(88 \%)$ of them were delivered by caesarean section; $6(12 \%)$ by forceps delivery. In controls 20 (20\%) developed fetal distress. Among the 20 cases of fetal distress, 18 (90\%) were 
Table 5: Perinatal Outcome in Oligohydramnios and Controls

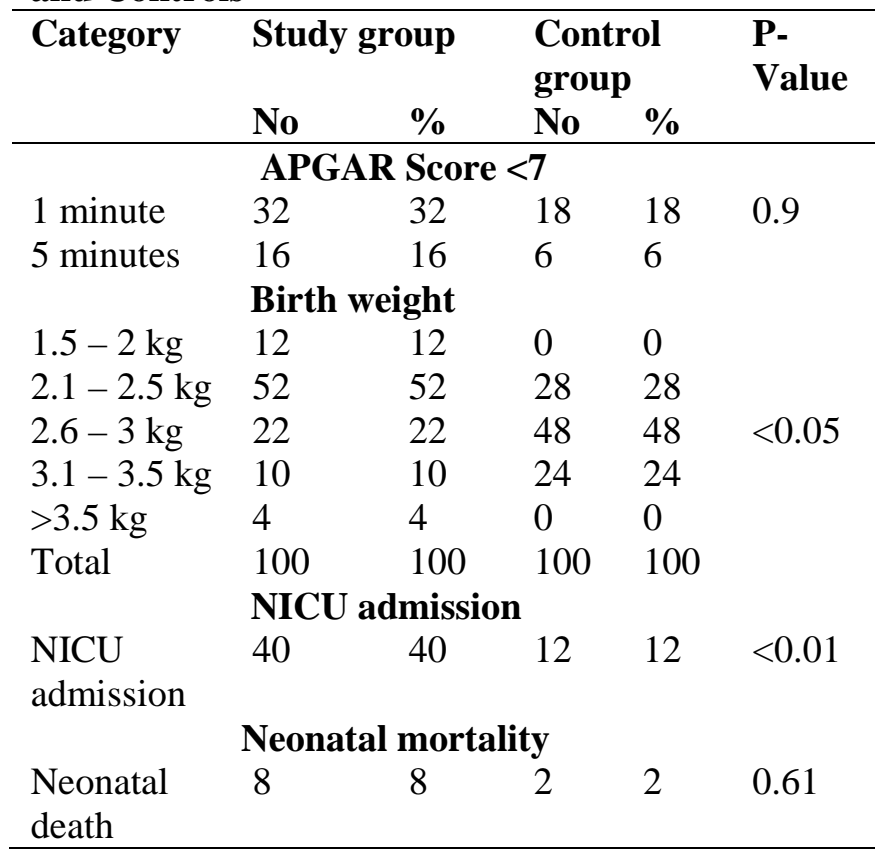

delivered by caesarean section and $2(10 \%)$ by forceps delivery. The difference was statistically non significant $(\mathrm{P}=0.98)$ [table 3 ].

The determination of AFI $\leq 5 \mathrm{~cm}$ as a screening test in predicting fetal distress during labor requiring caesarian delivery has a sensitivity of $72 \%$, specificity of $60 \%$, positive predictive value of $45 \%$ and negative predictive value of $82.5 \%$. A better sensitivity and negative predictive value makes it a good screening test. The occurrence of cesarean section rate was high in oligohydramnios group when associated with non reactive NST (52.6\%). Even when the NST was reactive in oligohydramnios $38.7 \%$ had LSCS (table 4).

The mean APGAR score in cases of oligohydramnios was 6.9 at 1 minute, 8.02 at 5 minutes. In controls, it was 7.8 at 1 minute and 9.2 at 5 minutes. The mean APGAR score and difference in the occurrence of APGAR score $<7$ was statistically not significant $(\mathrm{P}=0.9)$ [table 5]. The mean birth weight was $2.3 \mathrm{~kg}$ in oligohydramnios and $2.64 \mathrm{~kg}$ in control group. The difference in mean birth weight was not statistically significant. But, babies with birth weight $<2.5 \mathrm{~kg}$ were seen in $64 \%$ of oligohydramnios cases, whereas in controls, it was only $28 \%$.The occurrence of low birth weight $(<2.5 \mathrm{~kg})$ was statistically significant $(\mathrm{p}<0.05)$. In oligohydramnios, 20 babies $(20 \%)$ were admitted to NICU for various morbidities like, birth asphyxia, neonatal seizures and meconium aspiration syndrome, whereas in controls, only $12 \%$ admitted. The difference in the two groups was statistically significant $(\mathrm{p}<0.01)$. Difference in the neonatal deaths was nonsignificant between two groups $(p=0.61)$ [table 5].

\section{Discussion}

Various outcomes like age, parity, gestational age in our study are comparable with other Indian and Western studies ${ }^{3,4,5}$. The non-reactive NST rates are high in women with oligohydramnios. The rate of nonreactive NST is $38 \%$ in our study and is comparable to Meena Khatri et $\mathrm{al}^{4}$ and Krishna Jagatia et $\mathrm{al}^{5}$, who reported non-reactive NST rates to be $38 \%$ and $32 \%$ respectively.

Abnormal fetal heart rate in the form of variable and late decelerations during the intrapartum period indicates fetal distress and common in oligohydramnios. The variable and late decelerations FHR patterns noted in $60 \%$ in our study is more compared to $48 \%$ and $8 \%$ in studies by Casey et al ${ }^{6}$ and Sangeetha et $\mathrm{al}^{7}$ respectively. The meconium stained amniotic fluid is high in women with oligohydramnios. In our study thick meconium stained liquor was noted in $48 \%$ and is comparable to Preshit Chate et $\mathrm{al}^{4}$ who reported $46 \%$ of patient with grade III meconium stained amniotic fluid. Whereas, Sangeetha et $\mathrm{al}^{7}$ reported thick meconium stained amniotic fluid in only $18 \%$ of oligohydramnios cases.

Rates of LSCS for fetal distress in oligohydramnios vary in different studies. In our study, it was $88 \%$ and is more compared to Bhat $\mathrm{S}$ et $\mathrm{al}^{8}$ and Madhavi et $\mathrm{al}^{9}$ who reported $68 \%$ and $70 \%$ respectively. The efficacy of oligohydramnios in predicting fetal distress and requirement of LSCS had a sensitivity of $72 \%$ and specificity of $60 \%$, positive predictive value of $45 \%$ and negative predictive value of $82.5 \%$. In this study, a better sensitivity and negative predictive value makes it a good screening test. Sangeetha et $\mathrm{al}^{7}$ also concluded 
that it can be considered as a good screening test for the appearance of fetal distress in the intrapartum period requiring a cesarean delivery. The rate of LSCS was more with those with oligohydramnios and nonreactive NST (52\%). Even with reactive NST, 38\% developed fetal distress and LSCS was done, and is comparable to Krishna Jagatia et $\mathrm{al}^{5}$ and Sangeetha et $\mathrm{al}^{7}$.

The 5 minute APGAR Score $<7$ is seen in $16 \%$ of oligohydramnios group. This is in full agreement with studies by Vidyadhar B Bangal et $\mathrm{al}^{10}(16 \%)$, Bhat $\mathrm{S}$ et $\mathrm{al}^{8}$ and Krishna Jagatia et $\mathrm{al}^{5}(15 \%)$ and Madhavi et $\mathrm{al}^{9}$ (20\%). Newborns were admitted in the neonatal ward for various morbidities like birth asphyxia, meconium aspiration, etc in $40 \%$ of our cases is comparable to Preshit Chate et al of $42 \%$. But in studies by Bhat $\mathrm{S}$ et $\mathrm{al}^{8}$ and Krishna Jagatia et $\mathrm{al}^{5}$ NICU admission was comparatively less $28 \%$ and $22 \%$ respectively. Neonatal death in this study was $8 \%$. Whereas Krishna Jagatia et $\mathrm{al}^{5}$ reported $4 \%$, Chate et $\mathrm{al}^{4}$ reported $2 \%$ and Vidyadhar B Bangal et al ${ }^{10}$ reported higher percent of $24 \%$.

\section{Conclusion}

Oligohydramnios detected after 37 completed weeks of pregnancy is an indicator of poor pregnancy outcome. Non-reactive NST, intrapartum abnormal FHR tracing, thick meconium stained liquor, development of fetal distress, the rate of LSCS, low 5 minute APGAR score, low birth weight and perinatal mortality are high in cases of oligohydramnios.

\section{Acknowledgements}

We hereby would like to thank Dr. Suman Gaddi Professor and HOD, Department of OBG, Dr. Sreenivasalu the superintendent of VIMS, Dr. Krishna Swamy Director \& Principal VIMS, Bellary to allow us to publish this paper.

\section{Conflict of interest: None. Disclaimer: Nil.}

\section{References}

1.Umber A. Perinatal Outcome in Pregnancies Complicated by Isolated Oligohydramnios at Term. Annals. 2009; 15: 35-7.
2.Phelan JP, Smith CV, Broussard P, Small M. Amniotic fluid volume assessment using the four-quadrant technique in the pregnancy at 36-42 weeks gestation. $\mathrm{J}$ Reprod Med. 1987; 32(7): 540-2.

3.Sultana S, Akbar Khan MN, Khanum Akhtar KA, Aslam M. Low amniotic fluid index in high-risk pregnancy and poor apgar score at birth. J Coll Physicians Surg Pak. 2008; 18(10): 630-4.

4.Chate P, Khatri M, Hariharan C. Pregnancy outcome after diagnosis of oligohydramnios at term. Int $\mathrm{J}$ Reprod Contracept Obstet Gynecol. 2013; 2(1): 23-6.

5.Jagatia K, Singh N, Patel S. Maternal and fetal outcome in Oligohydramnios : A Study of 100 Cases. International Journal of Medical Science and Public Health. 2013; 2(3): 724-27.

6.Casey BM, McIntire DD, Bloom SL, Lucas MJ, Santos $\mathrm{R}$, et al. Pregnancy outcome after antepartum diagnosis of oligohydramnios at or beyond 34 weeks of gestation. Am J Obstet Gynecol. 2000; 182(4): 909-12.

7.Sangeetha K, Rao J, Ashwini AP, Kumar A. Pregnancy Outcome in Amniotic Fluid Index Less than 5 in Term Low-Risk Pregnancy. International Journal of Scientific Study. 2015; 3(3): 69-73.

8.Bhat S, Kulkarni V. Study of effect of Oligohydramnios on Maternal and Fetal Outcome. International Journal of Medical and Dental Sciences. IJMDS. 2015; 4(1): 582-88.

9.Madhavi K, Rao C. Clinical Study of Oligohydramnios, Mode of Delivery and Perinatal Outcome. IOSR Journal of Dental and Medical Sciences. 2015; 14(4): 6-11.

10.Bangal VB, Giri PA, Sali BM. Incidence of oligohydramnios during pregnancy and its effects on maternal and perinatal outcome. Journal of Pharmaceutical and Biomedical Sciences. 2011; 12(12): $1-4$.

Shiva Kumar H C Hiriyur Chidanandaiah ${ }^{1}$, Chandrashekhar $\mathrm{K}^{2}$, Suman Gaddi ${ }^{3}$, Chandrashekhar T Tharihalli ${ }^{4}$

${ }^{1}$ Associate Professor; ${ }^{2}$ Assistant Professor;

${ }^{3}$ Professor and HOD; ${ }^{4}$ Professor, Department of Obstetrics and Gynaecology, Vijayanagara Institute of Medical Sciences, Bellary, Karnataka, India. 